\title{
INNOVATIVE METHODS OF ARCHIVING, PRESENTATION AND PROVIDING ACCESS TO HISTOLOGICAL SECTIONS
}

\author{
Krystyna FILIPIAK, Agnieszka MALIŃSKA, Dariusz KRUPA, Maciej ZABEL \\ Department of Histology and Embryology, Poznań University of Medical Sciences, \\ Poland
}

DOI: 10.2478/v10052-011-0003-4

\begin{abstract}
Summary: The dynamic development of technical sciences and informatics makes now possible acquisition of microscopic images of histological sections, not only using digital cameras, but also through specialized devices called scanners. The digitalized images stored in a computer storage device are called virtual slides and, together with special software, are known as virtual microscopy. The virtual slides can be analyzed on a computer screen by panoramic viewing or using a detailed image examination at higher magnification. In many research and education institutions in both the U.S. and Europe, the virtual microscopy is used for teaching and training purposes. In the academic year of 2009/10, Department of Histology and Embryology, University of Medical Sciences in Poznan, as one of the first in Poland, has created a virtual database for educational purposes. This database created by archiving the traditional images of histological slides in the form of digital images. So far, more than 130 virtual slides have been acquired and catalogued in 24 thematic folders, available for medical students participating in histology, embryology and cell biology courses.

Telepathology is the second branch which uses virtual microscopy. Virtual microscope allows to discuss and resolve medical/diagnostic problems with the use of telecommunication systems and information technology. The existing internet platforms offer access to virtual microscopes and virtual slides. In June, 2011 the Center of Morphologic Images Archivization and Digital Database of Microscopic Pictures in the Department of Histology and Embryology, Poznan University of Medical Sciences has launched an online platform (www.caom.pl), aimed to provide the central database of scanned histological sections of physiological tissues, and pathological, rare and sporadic lesions, including tumors.
\end{abstract}

Key words: virtual microscopy, virtual slide, tele-medicine 


\section{INTRODUCTION}

The acquisition of microscopic images of cells and tissues is an important research tool, especially in medical and biological sciences. The turning point both in acquiring and archiving digital microscopic images were eighties of the twentieth century when it has started to be possible to connect a digital camera with a microscope and a computer. The dynamic development of technical sciences and computer technology now allows more precise acquisition of digital microscopic images of histological slides by specialized devices called scanners. The use of scanners allows to create databases of high quality histological images. These databases can be made available both for education purposes $[2,4,6,9,14,16,18$, $19,21]$ and diagnostic $[13,15,17,22,25]$. Furthermore, they are necessary for the functioning a new branch of medicine known as telemedicine, and especially such fields as the telepathology, tele-education, or telediagnostic $[3,4,10,26]$. Virtual microscopy using new interactive computer technologies provides wide opportunities for application in medicine.

\section{ACQUISITION OF MICROSCOPIC IMAGES}

\section{CCD camera as a tool for acquisition the digital microscopic images}

The first acquisitions of digital microscopic images were possible by coupling the microscope with a camera connected to a frame grabber which is an electronic device that captures individual frames. Depending on the type of the camera the captured images can have analog or digital format. The advantage of digital image over analog is the fact that they do not undergo the process of analogdigital conversion before sending them to the computer. This process is necessary in case of an analog image but leads to a partial loss of information as a consequence of conversion. The errors associated with image processing: quantization error, timing error, nonlinearity characteristics of processing.

A digital image (bitmap image, bitmap) is made up of units called pixels and the image is represented by a matrix of integers where each element (corresponding to one pixel of the image) has assigned the coordinates of its location in the image, and color or shade of gray. For images from the black and white cameras every shade of gray called gray level is described by a set of natural number from 0 to 255, proportional to the light intensity of a pixel. In the case of color images, the intensity is measured by its individual color components (usually red - R, a green - $\mathrm{G}$ and blue - B).

Currently, the microscopic images are captured using digital cameras with CCD matrix (CCD-charge-coupled device). CCD matrix consists of a lightsensitive elements (sensors, photodiodes) evenly distributed on a flat plate, whose 
job is to record the intensity of light coming from the individual elements of imaging object. In each sensor under the influence of the incident light the electric charge is created proportional to light intensity. The resulting electrical signal is processed by electronics to digital form. Each matrix element corresponds to adequate pixel in digital image. The first CCD camera was constructed in 1969 by Willard Boyle and George Smith at Bell Telephone Laboratories. This device consisted of eight photodiodes arranged in one row. In 1970 larger model with square matrix of 100x100 pixels was built. CCD sensors currently used are made of millions of light-sensitive elements, which affects the growth-resolution images.

The camera resolution expresses the number of sensors (pixels) in the matrix of rows and columns, such as $1300 \times 1030$ pixels, or $\sim 1,4$ million pixels (MP). The resolution power of the image increases with the number of photodiodes in the matrix. However it is limited by the microscope resolution. Therefore, important information on the microscopic images obtained from digital cameras is the number of microns per 1 pixel of image, for example $0,54 \mu \mathrm{m} /$ pixel or 1,08 $\mu \mathrm{m} /$ pixel [24]. Images generated by digital cameras are usually characterized by large size, defined as the amount of stored information. The size of the image depends on the following parameters: horizontal length $\mathrm{x}$ vertical length (expressed in pixels), binning factor, bit depth (number of bits used to encode the color of individual pixels) and color model. Assuming that a pixel occupies one byte of computer memory, the image from black and white CCD camera with 1300x1030 pixel matrix will occupy about $1.4 \mathrm{MB}$ (megabytes). Currently, cameras are widely used with a system of three matrices (so called 3-chip camera or 3CCD). Each matrix records the one component of RGB image, which not only allows for a color image, but also improves its quality.

The images of histological specimens captured with a digital camera coupled to the microscope are the kind of "digital photographs". They are an excellent form of documentation, not only because of their "indestructibility", but also easiness of cataloging and access and capabilities for fast sending to the consultation via internet. Images of histological specimens stored on electronic data stored device (e.g. CD or DVD) and attached to academic textbooks are a valuable supplement for written information. Evidence of the wide possibilities of using digital photographs of microscopic images is their presence on the internet [7]. Easy access to these web pages is particularly important for the self-study persons, including students. For example, on the homepage of the Department of Histology and Embryology, Poznań University of Medical Sciences (www.histologia.ump.edu.pl) there is the digital images gallery of selected parts of microscope slides. In addition, digital images can be used as reference images in the diagnosis of pathological cases [1]. Moreover it is possible to find on the internet selected and described by experts images of rare tumors (e.g. www.raretumours.org).

In the daily practice of histology and pathology there is a need for archiving images of, not only selected parts of the specimens, but its entire surface. 
It is now possible by microscopic systems equipped in CCD camera and the mechanical stage, whose movement is precisely controlled by electronic devices. Appropriate software allows to divide the surface of the specimen on equal areas: squares or rectangles and get the grid, for example, $8 \times 8$ or $10 \times 10$ images. Each image is captured with a margin larger than that determined by the grid field. The resulting images as constructed by stitching a sequential set of microscopic field images and analysis of their overlapping parts [11]. As a result the whole-slideimage is formed, also known as "mega-image" [11]. A mega-image stored on the computer hard disk can be viewed, analyzed and processed.

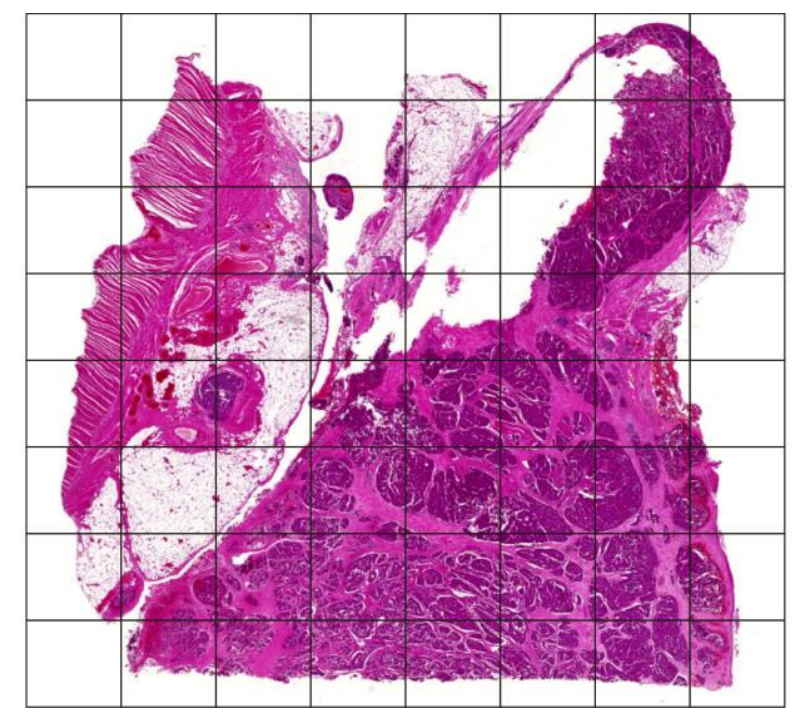

Fig.1. Whole slide image of the histological specimen with the gird using for capturing 64 parts of the slide.

\section{Slides scanner - a modern device for capturing and saving images of whole histological specimens}

Rising expectations of users of optical microscopes and the development of optoelectronic industries have contributed in construction of devices which combine function of optical microscope and digital camera - scanners of histological slides. These instruments allow to fully automated registration and digitalization of the whole histological slides. 


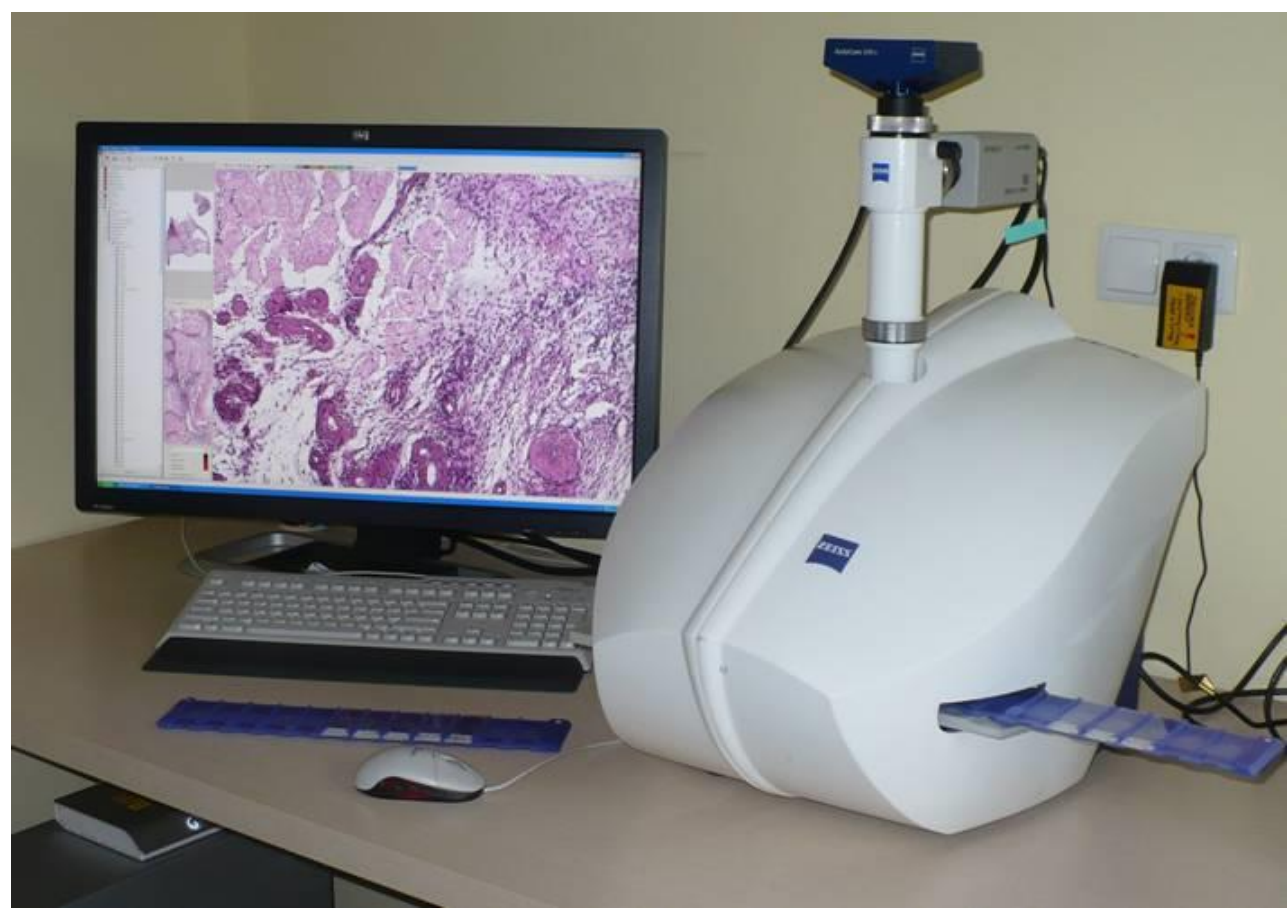

Fig. 2. Mirax-Midi scanner (Carl Zeiss) with a tray for maximum 12 histological specimens allows the automatic scanning and saving slides images as virtual slides.

The slide scanner in its design no is similar to a microscope (Fig. 2). It is a device which takes the microscope slide from the tray located back to it and places on a movable stage inside. Precise moving of stage in $\mathrm{X}, \mathrm{Y}$ and $\mathrm{Z}$ (focus) direction is controlled by electronic systems. Using a camera with the ability to quickly registering the entire image of the microscope slide is made. The user can see it on the computer screen and selects the area of interest. Then, using the high resolution 3 -chip CCD camera the device scans the area selected in the first stage of the scanning process. The scanner possesses a magnifying lens of 20x or 40x and autofocus function, which automatically focus the captured image. The whole slide image is formed similar to those acquired by motorized microscopes. The entire image of microscope slide is divided into smaller parts called tiles (Fig. 1) and each is captured and stored in the computer memory. After the scanning process, the resulting digital image of whole slide is saved on the computer hard drive or external data storage device of large memory.

An important technical issue is the use of slides and coverslips with a thickness of the range given by the scanner manufacturer, because that autofocus takes place in a small distance between magnifying lens and the slide. 


\section{VIRTUAL MICROSCOPY}

\section{Virtual slides}

Virtual slide is a digital record of the entire microscope specimen or imported part of it. The virtual slide stored in a computer database (hard disk, external data stored device, server) can be analyzed in any area, in a wide range of magnification directly on a computer monitor $[16,18]$. Due to the large size of the virtual slides (hundreds of $\mathrm{MB}$ ), their visualization and analysis require appropriate software. Such high specialized program is called virtual microscope $[8,15,16$, $19,21,25]$ and allowed both a panoramic observation of the microscopic specimen as well as detailed analysis of the selected part of tissue at higher magnification.

The preparation of virtual slides requires high-quality slides to scan: slides and cover slips with parameters specified by the manufacturer (uniform thickness), flat embedding, etc. Only well-prepared histological slide ensure the achievement of high-quality virtual slide.

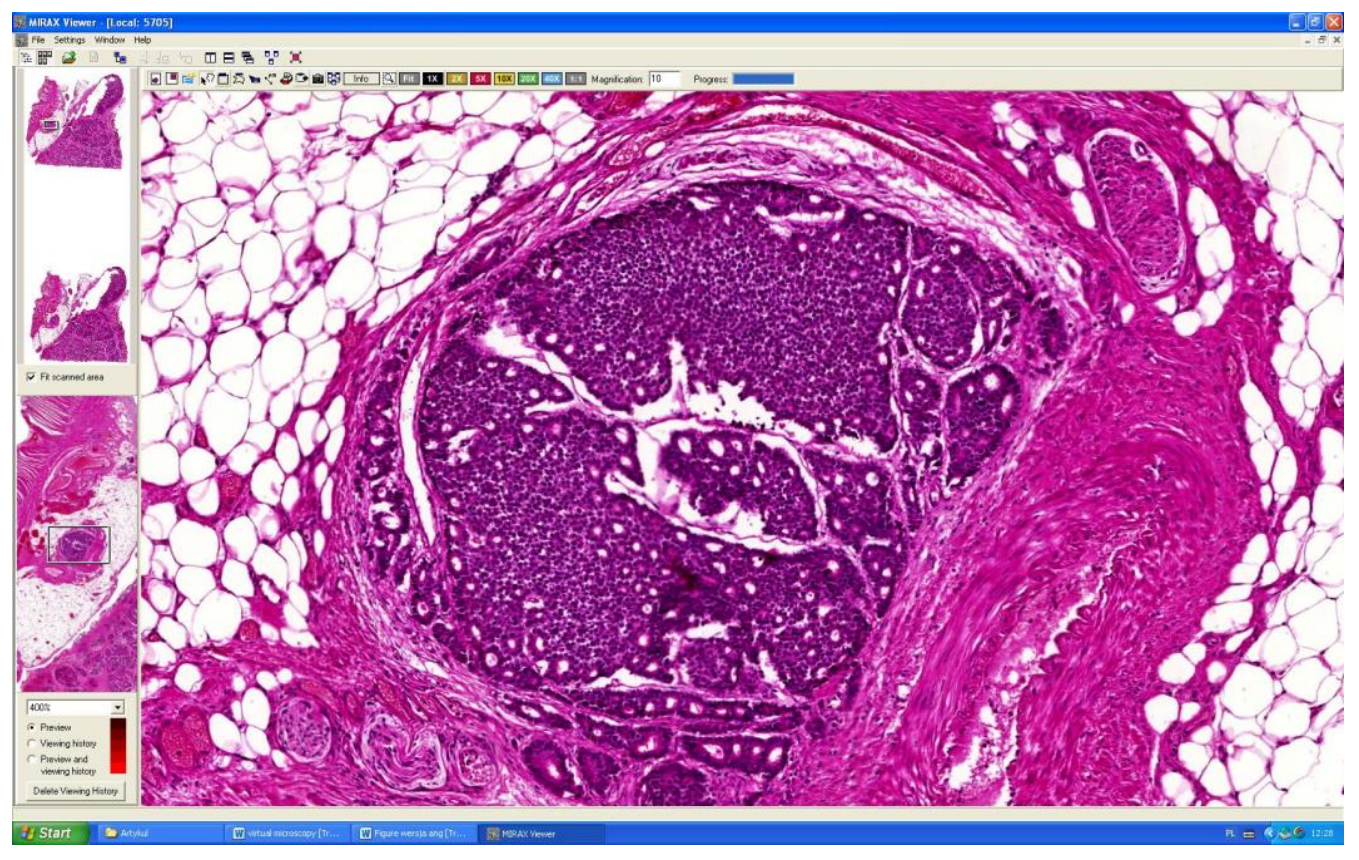

Fig. 3. The "print-screen" picture from virtual microscope Mirax Viewer (software Carl Zeiss). In the left upper corner the panoramic image of the whole specimen is presented. Bellow the rectangle indicates the part of image presented in the main window at high magnification.

Figure 3 shows a "print screen" of virtual microscope dialog box working with Mirax-Midi scanner (Carl Zeiss). In the upper left corner the panoramic image of the whole specimen is presented. Bellow the rectangle indicates the part of 
image presented in the main window at high magnification. At the time of analysis only a selected part of the image is loaded from the storage device and presented on the screen. Thus can be analyzed images of very good quality, due to their high resolution such as $2584 \times 1936$ pixels. Analysis of selected area can be done in magnification, which does not necessarily coincide with the standard lens microscope magnifications (e.g. 5x, 10x, 20x), but can be freely chosen in a stepwise or continuously from $0.2 x$ to $40 x$ magnification, as in this Mirax Viewer virtual microscope, Zeiss. It is possible to get more than $40 \mathrm{x}$ zoom, but it is already enlarged, which does not give additional information and only allows observation of each pixel of the image.

The main advantages of virtual microscopy are shown in the Table 1.

TABEL 1. Advantages and disadvantages of virtual microscopy.

\begin{tabular}{|c|c|c|c|}
\hline \multicolumn{4}{|c|}{ VIRTUAL MICROSCOPY } \\
\hline & ADVANTAGES & & DISADVANTAGES \\
\hline 1) & WHOLE SLIDE OBSERVATION & 1) & LONG TIME SCANNING \\
\hline 2) & $\begin{array}{l}\text { HIGH RESOLUTION AND HIGH } \\
\text { QUALITY OF IMAGES }\end{array}$ & 2) & LARGE SIZE OF COMPUTER FILES \\
\hline 3) & $\begin{array}{l}\text { EASY AND FAST MOVEMENT } \\
\text { BETWEEN DIFFERENT AREAS } \\
\text { OF THE IMAGE }\end{array}$ & 3) & $\begin{array}{l}\text { NECESSITY OF USING SPECIFIED } \\
\text { BY FACTORY PARAMETERS OF } \\
\text { SLIDES AND COVERSLIPS }\end{array}$ \\
\hline 4) & $\begin{array}{l}\text { WIDE RANGE OF } \\
\text { MAGNIFICATIONS AVAILABLE IN } \\
\text { BOTH DISCRETE AND }\end{array}$ & 4) & $\begin{array}{l}\text { NO UNIVERSALITY OF } \\
\text { RECORDED IMAGES FORMATS } \\
\text { AMONG THE SOFTWARE } \\
\text { PRODUCERS }\end{array}$ \\
\hline 5) & $\begin{array}{l}\text { CONTINUOUS MODE } \\
\text { REPEATABILITY OF PREZENTED } \\
\text { IMAGES }\end{array}$ & 5) & $\begin{array}{l}\text { NECESSITY OF COMPUTER } \\
\text { SYSTEM WITH HIGH RAM } \\
\text { MEMORY, GOOD RESOLUTION }\end{array}$ \\
\hline 6) & $\begin{array}{l}\text { POSSIBILITY TO ATTACH TEXT } \\
\text { ANNOTATIONS }\end{array}$ & & $\begin{array}{l}\text { MONITOR AND STORAGE DEVICE } \\
\text { OF HIGH CAPACITY }\end{array}$ \\
\hline
\end{tabular}

\section{Applications of virtual microscopy in education and medicine}

Virtual microscopy has found practical application especially in education. Due to the fact that the analysis of tissue structure is necessary in disciplines such as histology or pathomorhpology, digital slides seem to be particularly beneficial teaching tool. Many units, research and teaching both in the U.S. [4, 6, 9] and Europe $[14,16,23]$ used virtual microscopy for the education. It is useful teaching tool to improve the quality of education by the person conducting classes and seminars. The use of virtual slides for teaching avoids a number of disadvantages that are inherent with traditional light microscopy. Virtual microscopy provides a 
wide and easy access to the unique specimens documenting the pathological cases. Questionnaires conducted among students taking classes of medical subject like histology or pathology showed that they fully accept the virtual slides used as an alternative to routine histological specimens $[6,14,19]$.

The new field of education using virtual microscopy is education via the internet (e-learning). Virtual histological slides available on the websites allow to study outside the laboratory, at a time convenient to the student $[2,3,5,16]$.

In 2007 a European network for virtual microscopy was designed and tested. During this project, five academic servers across Europe were connected using a novel propagation method. This network was designed for sharing a database of virtual slides of several universities, and expands the speed and access to images [12].

At the academic year 2009/10 Department of Histology and Embryology, Poznan University of Medical Sciences, as one of the first units of research and teaching in Poland, has created a database of virtual slides for educational purposes. The traditional histological specimens have been registered and digitalized using scanner DotSlide, Olympus. Around 130 whole slide images has been collected and cataloged in 24 thematic folders accessible for medical students participating in histology, embryology and cytophysiology classes. The study room at The Department of Histology and Embryology has 80 computer stations that are equipped with OlyVIA software (v 2.1; Olympus). Intuitive use of this software lets quick and easy access to the virtual slides stored on the dedicated server. High quality digital images allow the observation and analysis of the organs and tissues structure. Students have opportunity to benefit from different magnification scales of the analyzed histological slides stained not only by routine methods, but also others for example immunohistochemical. In addition, virtual microscopy offers new possibilities for the organization of classes, innovative and more attractive methods of education and examination, which contribute to increasing the effectiveness of teaching.

Instead of education, virtual microscopy has also applications in telemedicine for discuss and resolve problems with the use of modern telecommunication systems. Depending on the way in which consultations may be performed, two types of telemedicine can be distinguished.

1. Telemedicine based on earlier recorded information of patient and sent along with the images to specialist (consultant) who analyzes them at any convenient time, then sends back with his opinion. This method based primarily on the e-mail contact brings the suitable information without need to organize a meeting or conference.

2. Real-time telemedicine (also known as online telemedicine). In this method, the requirements for technical equipment and network bandwidth are bigger than in the first type of telemedicine. An example can be video conference, which includes coverage of many physicians, such as first contact doctor and specialists. The big advantage of this method of consultation is that, both diagnosis and treatment 
recommendation arises in real time during the simultaneous discussion of all the participants.

Telemedicine involves various medical disciplines, among which we can distinguish teleradiology, telecardiology, teleoncology and others. One of the rapidly growing sub-fields of telemedicine is telepathology, the histological diagnosis at a distance using available modern telecommunication technologies [3, $15,21,18,26]$. Telepathology may be implemented in several ways: (1) sending selected part of microscopic images in digital form to the consultant and waiting for his answer, (2) analyzing of virtual histological slides from website by consultant and transvering back the diagnosis response (3) real-time transmission of images from the microscope to the consultant's computer $[1,18]$.

Based on the work of Janina Słodkowska "Virtual microscopy of the present pathology" [20] in the telepathology three sub-groups can be distinguished: (1) static telepathology based on digital images of selected part of microscopic fields sending via e-mail for consultation, (2) dynamic telepathology, which uses a system of transmission the microscopic images in real time to consultant computer for quick intraoperative diagnosis, (3) virtual telepathology based on analysis of virtual histological or pathological slides. Due to the growing need for multi and interdisciplinary consultation, it seems that virtual telepathology is a field that will soon become an integral part of telemedicine. This field opens the way for rapid consultation of difficult cases with specialists around the world, particularly important in developing countries, which do not have medical centers focused specialists, including pathologists [10].

\section{Internet platform as a place for sharing virtual slides, conducting real- time consultation, participating in remote microscopy over internet and multi-side collaboration}

Development of high-resolution whole slide imaging techniques gives new directions for histological or pathological laboratories by creating the possibility of using internet platforms with access to virtual microscopes. Internet platforms are used not only for histology and pathology teaching $[4,6,16]$, but above all create the possibility of consultation using virtual slides $[1,18,26]$, online discussion of rare pathological cases for proper diagnosis and scientific cooperation.

In June 2011 the Centre of Morphologic Images Archivization and Digital Database of Microscopic Pictures (CAOM) in the Department of Histology and Embryology, Poznan University of Medical Sciences has launched an online platform (www.caom.pl). The aim was to provide a central database of scanned histological slides covering the histological images of physiological organs and rare, sporadic cases of neoplastic lesions. CAOM portal allows to observation of virtual slides, usage of automated microscopes operated over internet and participate in online seminars. 
There are three levels of access to the portal: (1) for users - access to the general virtual slides database; (2) for moderators - who are granted access to the virtual slides sub-database for teleconsultations, can participate in teleconferences and teleconsultations, conduct seminars and operate remotely microscopes over internet; (3) for guests, visitors - access to the main website current information and the description of the project (without access to virtual slides databases).

Level (1) and (2) is available upon registration and verification by the administrator. Virtual slides viewing require Java applet or the free Mirax Viewer software (Carl Zeiss) installed on user's computer. This program provides access to digital images in a zvi format, so the user can perform image processing or generate a picture of the fragment of virtual slide as a jpeg or bmp image. So far CAOM database has more than 800 virtual slides that are stored on an independent server that guarantees the safety of the collected digital images. Figure 4 shows the part of CAOM virtual slides repository.

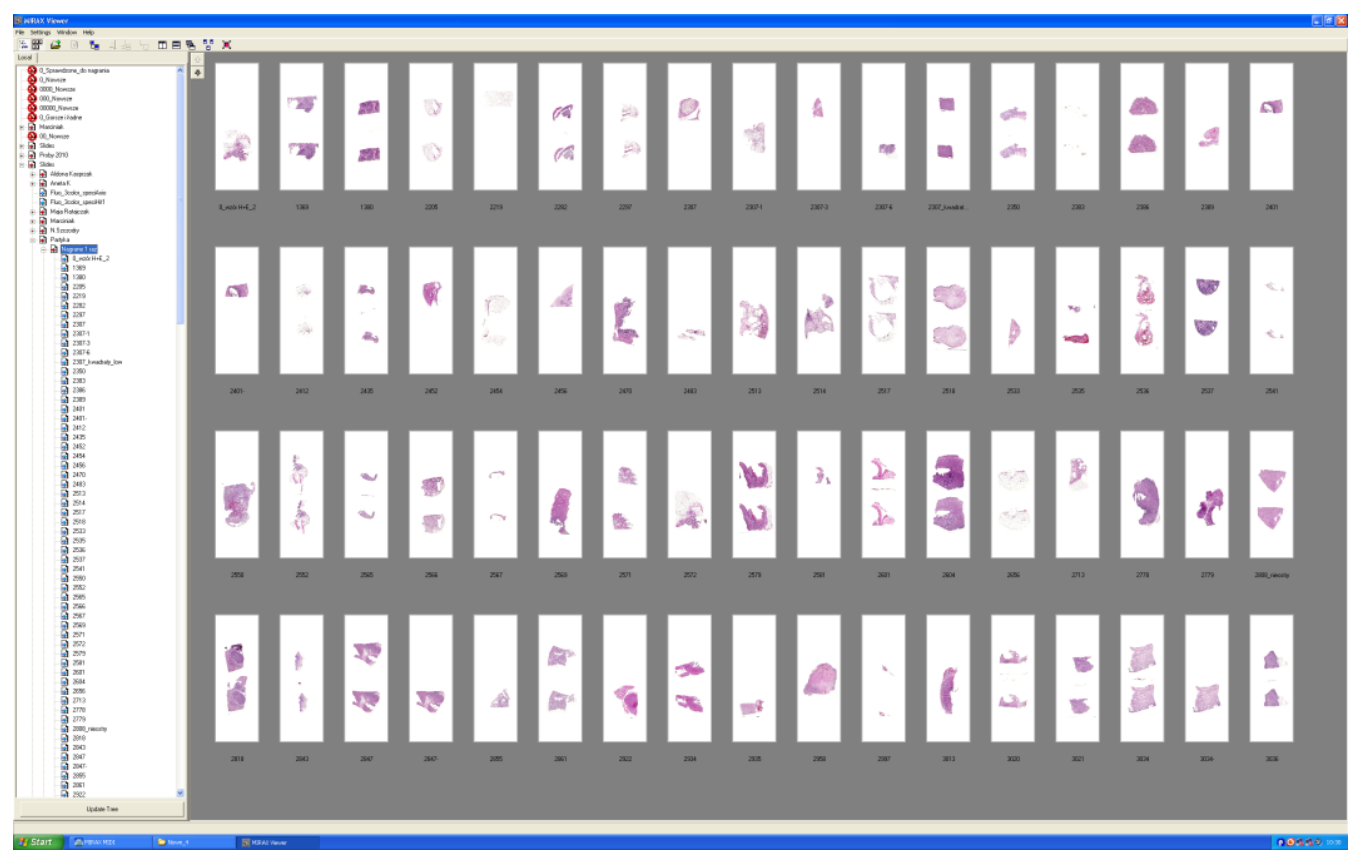

Fig.4. Part of CAOM virtual slides repository.

Moreover CAOM portal offers access to automated research microscopes. These microscopes are equipped with remote control software which combines the device over internet with the user. This software enables visualization of real time microscopic images on the computer and the communication between users connected to the server via a website. They are able to choose an interesting part of the specimen by moving the microscope stage, select the appropriate zoom and 
focus and communicate. There are two ways to communication: transfer of text messages between all logged on users or discourse via voice chat. The CAOM portal gives the access to Mirax Micro system designed and produced by Carl Zeiss. The system is based on motorized AxioImager 1 microscope, high resolution 3-chip CCD camera and Mirax Navigator software. This software allows connecting with microscope over internet, image viewing, image processing and communication between logged users (moderators).

In the near future the CAOM portal will also offer access to the tissue microarray database. Tissue microarray production can be performed in the Department of Histology and Embriology (Poznan University of Medical Sciences). Skilled operators using appropriate equipment (TMA Master from $3 D$ HISTECH firm) remove fragment of tissue from the donor block and insert it into recipient block. Employing this method it is possible to have several dozen of various biopsies (diameter about 1 or $2 \mathrm{~mm}$ each) on one slide. These slides can be distribute free of charge among the scientific community in Poland. The microarrays slides after staining can be scanned and saved as virtual slides on the CAOM website. The above-mentioned microarrays are currently one of the priority research tools in the differential diagnosis and comparison of lesions useful for medical specialists including morphologists and pathologists.

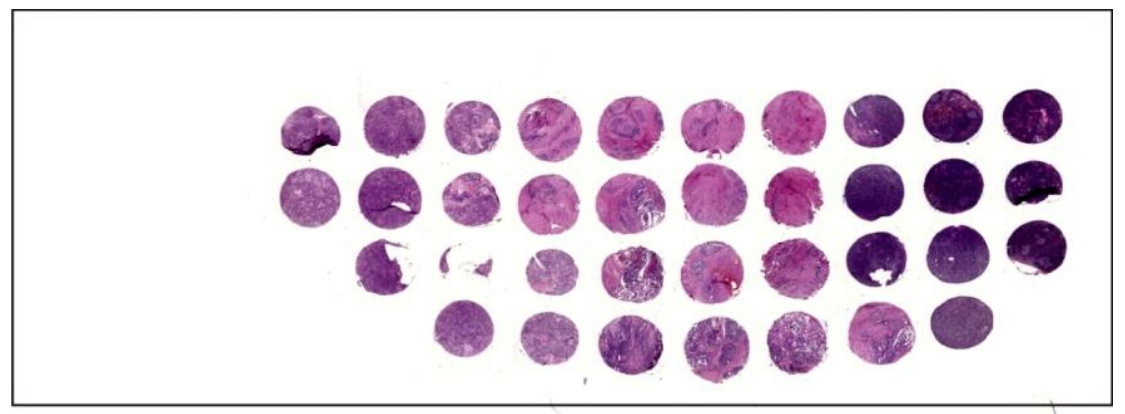

Fig. 5. The example of tissue microarray stained using H+E method.

\section{SUMMARY}

Digitization and archiving of microscopic images in medicine plays a dual role. First passive, is associated with digital image processing of microscopic pictures, depositing them on the server and giving wide access to the final product for external users. Much more interesting, also from the standpoint of cell biology researcher, is the active aspect of digitization. The practice of recent years shows that the digital microscopic images depicting the static model of the cell (tissue) becomes the starting point to exchange of views between users of specialized web 
portals. In this way, sharing the results of their observations in the form of high quality images becomes a very effective tool for the dissemination of scientific discoveries and conducting substantive discussions about strategies of research.

\section{ACKNOWLEDGEMENT}

This publication is part of project NR13 000606 supported by The National Centre for Research and Development.

\section{REFERENCES}

[1] BONDI A, PIEROTTI P, CRUCITTI P, LEGA S. The virtual slide in the promotion of cytologic and histologic quality in oncologic screenings. Ann Ist Super Sanita 2010; 46: 144-50.

[2] COLEMAN R. Can histology and pathology be taught without microscopes? The advantages and disadvantages of virtual histology. Acta Histochem 2009; 111: 1-4.

[3] DEE FR. Virtual microscopy for comparative pathology. Toxicol Pathol 2006; 34: 966-67.

[4] DEE FR. Virtual microscopy in pathology education. Hum Pathol 2009; 40: 1112-1121.

[5] FEIT J. MATYYSKÄ L, ULMAN V, HEJTMÁNEK L, JEDLIČKOVÁ H, JEŽOVÁ M, MOULIS M, FEITOVÁ V. Virtual microscope interface to high resolution histological images. Diagn Pathol 2008; $3:$ S10.

[6] FÓNYAD L, GERELY L, CSERNEKY M, MOLNÁR B, MATOLSCY A. Shifting gears higher digital slides in graduate education -4 years experience at Semmelweis University. Diagn Pathol 2010; 5: 73- 81.

[7] GABRIL MY, YOUSEF GM. Informatics for practicing anatomical pathologists: marking a new era in pathology practice. Mod Pathol. 2010; 23: 349-58.

[8] GIANSANTI D, GRIGIONI M, D'AVENIO G, MORELLI S, MACCIONI G, BONDI A, GIOVAGNOLI MR. Virtual microscopy and digital cytology: state of the art. Ann Ist Super Sanità 2010; 46: 115-22.

[9] GOLDBERG HR, DINTZIS R. The positive impact of team-based virtual microscopy on student learning in physiology and histology. Am J Physiol 2007; 31: $261-65$.

[10] HITCHCOCK C. The future of telepathology for the developing world. Arch Pathol Lab Med 2011; 135: 211-14.

[11] IREGUI M, GÓMEZ F, ROMERO E. Strategies for efficient virtual microscopy in pathological samples using JPEG2000. Micron 2007; 38: 700-13.

[12] LUNDIN M, SZYMMAS J, LINDER E, BECK H, de WILDE P, VAN KRIEKEN H, GARCÍA ROJO M, MORENO I, ARIZA A, TUZLALI S, DERVIŞOĞLU S, HELIN H, LEHTO VP, LUNDIN J. A. European network for virtual microscopy--design, implementation and evaluation of performance. Virchows Arch 2009; 454: 421-29.

[13] MARCHEVSKY AM, KHURANA R, PREMI T, SCHARRE K, FARIAS P, BOSE S. The use of virtual microscopy for proficiency testing in gynecologic cytopathology: A feasibility study using ScanScope. Arch Pathol Lab Med 2006; 130: 349-55.

[14] MERK M, KNUECHEL R, PEREZ-BOUZA A. Web-based virtual microscopy at the RWTH Aachen. University: Didactic concept, methods and analysis of acceptance by the students. Anat Anz 2010; 192: 383-87.

[15] NIELSEN PS, LINDEBJERG J, RASMUSSEN J, STARKLINT H, WALDSTRØM M, NIELSEN B. Virtual microscopy: an evaluation of its validity and diagnostic performance in routine histologic diagnosis of skin tumors. Human Pathol 2010; 41: 1770-76. 
[16] PAULSEN FP, EICHHORN M, BRÄUER L. Virtual microscopy - the future of teaching histology in the medical curriculum? Ann Anat 2010; 192: 378-82.

[17] PINCO J, GOULART RA, OTIS CN, GARB J, PANTANOWITZ L. Impact of digital image manipulation in cytology. Arch Pathol Lab Med 2009; 133: 57-61.

[18] ROCHA R, VASSALLO J, SOARES F, MILLER K, GOBBI H. Digital slides: Present status of a tool for consultation, teaching, and quality control in pathology. Pathol Res Pract 2009; 205: 735-41.

[19] SCOVILLE SA, BUSKIRK TD. Traditional and virtual microscopy compared experimentally in a classroom setting. Clin Anat 2007; 20: 565-70.

[20] SŁODKOWSKA J. Mikroskopia wirtualna we współczesnej patologii. Przew Lek 2008; 1: 290-95.

[21] STEWART J, BEVANS-WILKINS K, BHATTACHARYA A, YE C, MIYAZAKI K, KURTYCZ DFI. Virtual Microscopy: An educator's tool for the enhancement of cytotechnology students' locator skills. Diagn Cytopathol 2008; 36: 363-68.

[22] STEWART J, MIYAZAKI BS K, BEVANS-WILKINS K, YE C, KURTYCZ DFJ, SELVAGGI SM. Virtual microscopy for cytology proficiency testing: Are we there yet? Cancer 2007; 11: 203-9.

[23] SZYMAS J, LUNDIN M. Five years of experience teaching pathology to dental students using WebMicroscope. Diagn Pathol 2011; 6: S13.

[24] WEINSTEIN RS, GRAHAM AR, RICHTER LC, BARKER GP, KRUPINSKI EA, LOPEZ AM, ERPS KA, BHATTACHARYYA AK, YAGI Y, GILBERTSON JR. Overview of telepathology, virtual microscopy, and whole slide imaging: prospects for the future. Hum Pathol 2009; $\overline{40: 1057-69 .}$

[25] WIENERT S, BEIL M, SAEGER K, HUFNAGL P, SCHRADER T. Integration and acceleration of virtual microscopy as the key to successful implementation into the routine diagnostic process Diagn Pathol 2009; 4: 3-10.

[26] WILBUR D, MADI K, COLVIN RB, DUNCAN LM, FAQUIN WC, FERRY JF, FROSCH MP, HOUSER SL; KRADIN RL, LAUWERS GY, LOUIS DN, MARK EJ, MINO-KENUDSON M, MISDRAJI J, NIELSEN GP, PITMAN MB, ROSENBERG AE, SMITH N, SOHANI AR, STONE JR, TAMBOURET RH, WU CL, YOUNG RH, ZEMBOWICZ A, KLIETMANN W. Whole-slide imaging digital pathology as a platform for teleconsultation. A pilot study using paired subspecialist correlations. Arch Pathol Lab Med 2009; 133: 1949-53.

Corresponding author: Krystyna Filipiak

Poznań Univeristy of Medical Sciences

6 Święcickiego Str., 60-781 Poznań, Poland

phone: +48618546446

e-mail: kfilip@ump.edu.pl 